\title{
Determination of Morin by Using a Briggs-Rauscher Oscillator
}

\author{
Waqar Uddin ${ }^{l}$, Gang $H u^{l, *}$, Xuanxuan Sun ${ }^{1}$, Saif Ullah ${ }^{1}$, Saira Sardar ${ }^{2}$, Zhang Wangning ${ }^{1}$, and \\ Muhammad Yasir Nawabi ${ }^{1}$ \\ ${ }^{1}$ Department of Chemistry, Anhui University, Hefei, 230601, People's Republic of China \\ ${ }^{2}$ Institute of Chemical Sciences, University of Peshawar, Pakistan \\ *E-mail: hugang@ustc.edu
}

doi: $10.20964 / 2018.01 .82$

Received: 4 October 2017 / Accepted: 24 November 2017 / Published: 16 December 2017

\begin{abstract}
A suitable and convenient method for the analytical determination of morin was established by using Briggs-Rauscher chemical matrix (BR) in the paper. The macrocyclic Ni-complex $[\mathrm{NiL}]\left(\mathrm{ClO}_{4}\right)_{2}$ was used as catalyst. The ligand $\mathrm{L}$ in the complex is 5,7,7,12,14,14-hexamethyl-1,4,8,11tetraazacyclotetradeca-4,11-diene. Experimental data has absolutely indicated the inhibitory effect caused by morin on the active BR system. Different concentrations of morin ranging from $2.44 \times 10^{-6}$ $\mathrm{mol} / \mathrm{L}$ to $1.30 \times 10^{-5} \mathrm{~mol} / \mathrm{L}$ have been tested. As a result, oscillating system stopped to oscillate for some instant and then successfully regenerated. Such phenomenon has concentration dependent, meaning as the concentration of morin were increased, the inhibition time $\left(t_{i n}\right)$ of the system were increased and vice versa. Thus, by plotting $t_{\text {in }}$ against concentrations of morin, a linear regression curve was obtained over a concentration range from $2.44 \times 10^{-6} \mathrm{~mol} / \mathrm{L}$ to $1.30 \times 10^{-5} \mathrm{~mol} / \mathrm{L}$ of morin with correlation coefficient of 0.98 . The calculated RSD value is $2.56 \%$, which was obtained by the 5measurements of $1.30 \times 10^{-5} \mathrm{~mol} / \mathrm{L}$ morin. Although the reaction of morin and $\mathrm{KIO}_{3}$ was confirm through cyclic voltammetry experiment, actually the $t_{\text {in }}$ was caused due to the reaction of morin with $\mathrm{HOO}^{\circ}$ radical (produced during oscillatory reaction).
\end{abstract}

Keywords: Briggs-Rauscher, Electrochemical Oscillator, Morin, Inhibitory effect

\section{FULL TEXT}

(C) 2018 The Authors. Published by ESG (www.electrochemsci.org). This article is an open access article distributed under the terms and conditions of the Creative Commons Attribution license (http://creativecommons.org/licenses/by/4.0/). 